\title{
The transformation of the academic publishing market: multiple perspectives on innovation
}

\author{
Diego Ponte $^{1}$ (D) Bozena I. Mierzejewska ${ }^{2} \cdot$ Stefan Klein $^{3}$
}

Received: 15 February 2017 / Accepted: 16 February 2017 / Published online: 7 March 2017

(C) Institute of Applied Informatics at University of Leipzig 2017

This special issue of Electronic Markets focuses on the transformation of the academic publishing market. This theme falls within the larger topic of the innovations triggered by the digital transformation, which is witnessing an increasing level of academic attention. In recent years Electronic Markets has published a series of editorials devoted to digital transformation in academic publishing: on reviewing (Alt et al. 2015), on self-archiving (Alt et al. 2016a), as well as on quantitative measures in academic publishing (Alt et al. 2016b). A number of other journals have published special issues devoted to investigate a variety of aspects related to academic publishing. ${ }^{1}$ This growing interest can be interpreted as the increase of awareness of issues related to both, the academic publishing process and the publishing market, and also as raising need for data supported evidence of current trends and the need for an

\footnotetext{
${ }^{1}$ Special issues focused on academic publishing have been published by Educational Philosophy and Theory (2015), Nature (2013), Economic Analysis and Policy (2009).
}

Diego Ponte

diego.ponte@unitn.it

Bozena I. Mierzejewska

bmierzejewska@fordham.edu

Stefan Klein

stefan.klein@uni-muenster.de

1 Department of Economics and Management, University of Trento, Via Inama 5, 38122 Trento, Italy

2 Gabelli School of Business, Fordham University, 45 Columbus Avenue, New York, NY 10023, USA

3 School of Business and Economics, University of Münster, Leonardo Campus 11, 48149 Münster, Germany open discussion about the consequences for all involved in the process of scholarly communication.

Academic publishing has been profoundly affected by a plethora of innovations that have shaped the way scientific knowledge is produced, evaluated and disseminated. Services such as SSRN, Google Scholar, ResearchGate, Academia.edu, Mendeley and the Open Access journals are only the visible tips of the iceberg of new players and indeed new services and modes of publishing. Innovations in this industry can be identified at different levels:

- Infrastructural level: the transformation of competition in the academic publishing market has been shaped by a) new entrants, b) disruptive innovations such as open access (Lewis 2012), c) new digital-only formats and platforms for academic publishing, d) increasingly adopted social-based platforms of sharing and communicating, and e) innovative technology-based forms of ranking the "quality" of scientific knowledge. This might cause a shift in the market power of the actors.

- Firms and strategy level: firms in the sector are using new business models and strategies to offer their services. In this sense, the existing competitive strategies of the firms are heavily shaped by innovative forms of pricing, bundling and by new types of value proposition. The digital value chain gives strategic relevance to different phases and components compared to the old paper-based value chain. Furthermore, the growing attention given to the technology-driven forms of sharing and ranking of scientific work has pushed traditional intermediaries to consider these technologies and tools in their strategies (Ponte and Klein 2017).

- Actors level: the transformation of the production and consumption chain of scientific knowledge implies new roles and new linkages among the actors of the scientific 
ecosystem. The sector is changing as the stakeholders (authors, readers, reviewers, editors, publishers, libraries, universities, political institutions, etc....) (re-)position themselves in a growing cybermediated market that emphasizes prosuming.

Therefore, it can be argued that innovations across all levels are affecting all steps in the scholarly communication process and influences the culture that shapes academic research practice. These changes and disruptions have become observable from different vantage points.

First, the search of scientific knowledge has become more interactive and web based. The ways scholars nowadays search for new material is based on topics and names of authors rather than locating already known journals. Recent surveys have revealed the central importance of general purpose search engines and Google scholar (Nicholas et al. 2017; Wolff et al. 2016).

Second, the shift to the web has disrupted many of the physical barriers native to the paper-based market. As a fact, the publication process is not anymore under the total control of scientific publishers; alternative publication initiatives as the publication infrastructure has become more fragmented (Crouzier 2015). Among others, there is a number of free (quality) services offered by an increasing number of stakeholders: Google Scholar, Mendeley, ResearchGate etc. (Ware and Mabe 2015).

Third, the leading publishing houses have made significant investments into the digital publishing infrastructures. For example, in 2013 the leading publishing house Elsevier acquired Mendeley (Lunden 2013; Bonasio 2013), SSRN in 2016 (Gordon 2016) and in early 2017 it acquired Plum Analytics a leading provider of altmetrics (Elsevier 2017); in 2015, the publishing house Springer acquired MacMillan to become the second scientific publishing giant (Van Noorden 2015). Those developments may be good for the viability and growth of these services; however concerns have been raised regarding their ongoing independence and the unprecedented opportunities for reader surveillance by the publishers (Schonfeld 2017).

Fourth, new technology-based reputation mechanisms have been diffused widely across the ecosystem to evaluate the performance of authors and the quality of a scientific journal. In particular, the landscape of academic metrics has been rapidly evolving and subject of much debate about their use (DeSanto and Nichols 2016; Haustein 2016).

Fifth, the ease of publishing combined with the global trend to regard publications in highly ranked journals as gold standard of academic qualification and performance has unsurprisingly created side effects and misconducts. Fake data and plagiarism have become growing problems in the sector and the retraction of papers from scientific publishers is becoming a common practice (Steen et al. 2013). The responses (or remedies) are technologically facilitated practices aiming at transparency of scientific data and results on the one hand and automatic checking for plagiarism on the other (WeberWulff 2016).

Sixth, social networks are shaping the way scholars search for and disseminate scientific knowledge. Further, "massively collaborative science" and "citizen science" are also impacting the organization of research (Franzoni and Sauermann 2014).

These examples illustrate that many of the established themes of digital transformation - social media, business model and service innovation, disintermediation, cybermediation, prosuming, new pricing models - have become discernible in distinct ways in this industry. The ongoing transformation conveys the impression that disruptive innovations are under way, which typically threaten the incumbents. Yet, Bo-Christer Björk in this special issue provides a strategic analysis of the market, which explains the increasing concentration of the market as well as influence and market share of the dominant incumbent publishing houses. Based on his analysis we would like to highlight three explanations for the increasing concentration and market power of the leading publishing houses: First, the (end-)customers of academic publishing (the readers) are typically also authors and editors or reviewers and thus need - ideally unrestricted - access to existing publications. Yet they are usually not aware of the cost of literature access and shielded from the direct effects of price increases as in most academic institutions access to literature is regarded as part of the infrastructure and therefore covered by institutional budgets. Therefore, most authors have stronger incentives to publish in highly ranked journals, despite concerns about publishers' pricing and copyright policies, rather than to favor open-access publication outlets despite significant campaigns, e.g. by the EU Commission and a number member states to promote open access outlets.

Second, these publishing houses have not only achieved a high market concentration (Larivière et al. 2015; Monbiot 2011) but they have created a de facto monopoly by controlling access (rights) to their expanding digital archives. Subscription contracts do no longer convey ownership of printed journals (or digital copies) to subscribers, but typically only usage rights linked to the contract period. In this global market, a highly concentrated supply side faces a highly fragmented buy side, primarily academic institutions. Not surprisingly, this situation has led to significant price increases for access rights to huge digital repositories. From an economic perspective, the publishing houses pursue a rational strategy to continually expand their digital repositories and exploit the monopoly vis-à-vis their customers: an unbeatable business model given the dependency of the academic institutions on access to the journals.

Third, the academic institutions have become trapped in a vicious cycle: their reputation as research institutions depends 
on extensive - and increasingly expansive - access to digital repositories, which have been built based on research and reviewing almost exclusively funded by the very same institutions. The larger the repositories and the higher the reputation of the journals included, which is almost exclusively based on the quality of academic work, the higher the dependence on the publishers.

In order to level the playing field somewhat, academic institutions in various countries, e.g. the UK (Earney 2016), Netherlands (Wijkhuijs 2015) and Germany have created alliances as an act of collective action in order to jointly negotiate with the publishers. E.g., the German project DEAL ${ }^{2}$ aims at Germany-wide licenses including an open access component from the large academic publishing houses, in other words a significant modification of the publishers' business models. In late November 2016, DEAL's negotiations with Elsevier stalled and access to the Elsevier repositories have become severely disrupted for scholars throughout Germany as of January 2017 (Vogel 2017).

While they have successfully increased market share and profits, some of the leading publishing houses have caused concerns about abuse of a dominant market position (Eve 2016). They seem to have changed priorities and focused less on what it means to be an academic publisher responsible to its stakeholders: serving the academic community and society at large, providing affordable and transparent access to information that authors has entrusted them with for the greater good of society.

While the digital transformation has been contributing to profound innovations of how academics collect data, find and access research materials, how they share, collaborate and disseminate their work, at the same time it has increased the paywalls between consumers and content creators. The papers of this special issue take stock of the transformation, identify and articulate distinctive patterns of change in this market.

In his opinion piece, Bo-Christer Björk, (Björk 2017) focuses attention at the strategic level by exploring the transition of the sector from paywall to open access. By conducting a strategic analysis of Porter's five forces model to examine the situation of the sector, the author shows that even if open access gathered momentum from national and international institutions, it has not become the mainstream publishing model yet.

Matt and his colleagues (Matt et al. 2017) focus on both infrastructure and authors' level by investigating one of the most critical phases of scientific publishing: the scientific knowledge quality assessment. The authors focus on the perceptions and drivers that might push researchers using alternative review systems such as the social peer review (SPR). By means of a survey sent to scholars, they show that the adoption of SPR is driven more by extrinsic factors than by intrinsic ones and they argue that this social form of peer review will hardly change the situation in the short run.

\footnotetext{
${ }^{2}$ www.projekt-deal.de
}

Laakso and his colleagues (Laakso et al. 2017) explore acceptance and use of one of the most disruptive elements of scientific publishing: Academic Social Networks (ASN). By using an empirical approach based on bibliometric analysis, interviews and surveys, the authors state that ASNs are becoming a major way for researchers to market their own work even in the face of copyright breaches.

Overall, the articles published in this special issue highlight facets of digital transformation in the particular market segment of academic publishing, in which our readers are stakeholders and participating observers. One should ask a question - what could be a way forward in discussing and finding solutions to the emergent issues affecting scholars, libraries and general public. To the guest co-editors of this special issue, it seems that the general awareness of economic and technological pressures on the scholarly ecosystem is relatively low. Too many academics have no information about the licensing costs of access to the materials they use, and anecdotal evidence from academic conferences suggest that they do not seem to be interested. Librarians and infrastructure providers need to work closely with faculty and active researchers to provide transparency about enduring costs and the current market situation. Discussion about long-term effects of digital transformation should be raised by university leaders, and those who provide funds maintaining university structures - research funding bodies, taxpayers and general public.

With this special issue, we hope to add maybe a small, but still important, contribution to the understanding of the ongoing transformation from a customer as well as a supplier perspective. We aimed to use economic and strategic rationales to explore trends of innovation and market transformation on the one side and changing patterns of production and use of academic literature as well as initiatives of collective action on the other. Finding a solution to this riddle will help to achieve healthy, innovative market of academic publishing.

\section{References}

Alt, R., Militzer-Horstmann, C., \& Zimmermann, H. D. (2015). Editorial 25/4: Electronic markets on reviewing. Electronic Markets, 25(4), 255-261.

Alt, R., Militzer-Horstmann, C., \& Zimmermann, H. D. (2016a). Electronic markets on self-archiving. Electronic Markets, 26(1), 1-5.

Alt, R., Militzer-Horstmann, C., \& Zimmermann, H. D. (2016b). Electronic markets on the impact factor. Electronic Markets, 26(2), 95-101.

Björk, B. C. (2017). Scholarly journal publishing in transition-from restricted to open access. Electronic Markets, 1-9. doi:10.1007 /s12525-017-0249-2.

Bonasio, A. (2013). Q\&A: team Mendeley joins Elsevier (April 9, 2013). Available at: http://blog.mendeley.com/press-release/qa-teammendeley-joins-elsevier/.

Crouzier, T. (2015). Science Ecosystem 2.0: How will change occur? European Union. ISBN 978-92-79-50356-6. 
DeSanto, D., \& Nichols, A. (2016). Scholarly metrics baseline: A survey of faculty knowledge, use, and opinion about scholarly metrics. College \& Research Libraries, 78(2), 150-170.

Earney, L. (2016). Jisc Collections and Elsevier Agreement: Questions and Answers (November 28, 2016). Available at: https://www.jisc. ac.uk/blog/jisc-collections-and-elsevier-agreement-questions-andanswers-28-nov-2016.

Elsevier (2017). Elsevier Acquires Leading 'Altmetrics' Provider Plum Analytics. Available at: https://www.elsevier.com/about/pressreleases/corporate/elsevier-acquires-leading-altmetrics-providerplum-analytics.

Eve, M. P. (2016). Referring Elsevier/RELX to the Competition and Markets Authority, martineve.Com (December 03, 2016). Available at https://www.martineve.com/2016/12/03/referringelsevierrelx-to-the-competition-and-markets-authority/.

Franzoni, C., \& Sauermann, H. (2014). Crowd science: The organization of scientific research in open collaborative projects. Research Policy, 43(1), 1-20.

Gordon, G. (2016). SSRN - the leading social science and humanities repository and online community-joins Elsevier (May 17, 2016). Available at https://www.elsevier.com/connect/ssrn-the-leadingsocial-science-and-humanities-repository-and-online-communityjoins-elsevier.

Haustein, S. (2016). Grand challenges in altmetrics: Heterogeneity, data quality and dependencies. Scientometrics, 108(1), 413-423.

Laakso, M., Lindman, J., Shen, C., Nyman, L., \& Björk, B. C. (2017). Research output availability on academic social networks: Implications for stakeholders in academic publishing. Electronic Markets, 1-9. doi:10.1007/s12525-016-0242-1.

Larivière, V., Haustein, S., \& Mongeon, P. (2015). The oligopoly of academic publishers in the digital era. PloS One, 10(6), e 0127502.

Lewis, D. W. (2012). The inevitability of open access. College \& Research Libraries, 73(5), 493-506.

Lunden, I. (2013). Confirmed: Elsevier has bought Mendeley for $\$ 69 \mathrm{M}-$ $\$ 100 \mathrm{M}$ to expand its open. Social education data efforts, Techcrunch.com (April 8, 2013). Available at https://techcrunch. com/2013/04/08/confirmed-elsevier-has-bought-mendeley-for-69 m-100m-to-expand-open-social-education-data-efforts/.

Matt, C., Hoerndlein, C., \& Hess, T. (2017). Let the crowd be my peers? How researchers assess the prospects of social peer review. Electronic Markets, 1-14. doi:10.1007/s12525-017-0247-4.
Monbiot, G. (2011). Academic publishers make Murdoch look like a socialist. The Guardian, (August 29, 2011). Available at: https://www.theguardian.com/commentisfree/2011/aug/29 /academic-publishers-murdoch-socialist.

Nicholas, D., Boukacem-Zeghmouri, C., Rodríguez-Bravo, B., Xu, J., Watkinson, A., Abrizah, A., Herman, E. and Świgoń, M. (2017). Where and how early career researchers find scholarly information. Learned Publishing, 30, 19-29. doi:10.1002/leap.1087.

Ponte, D., \& Klein, S. (2017). Research and web 2.0: Technology, innovation, and actor constellations. In A. Esposito (Ed.), Research 2.0 and the impact of digital technologies on scholarly inquiry (pp. 1731). Hershey, PA: IGI Global.

Schonfeld, R. C. (2017). When is a Publisher not a Publisher? Cobbling together the pieces to build a workflow business, The Scholarly Kitchen (February 9, 2017). Available at: https://scholarlykitchen.sspnet.org/2017/02/09/cobbling-togetherworkflow-businesses/.

Steen, R. G., Casadevall, A., \& Fang, F. C. (2013). Why has the number of scientific retractions increased? PloS One, 8(7), e68397.

Van Noorden, R. (2015). Nature owner merges with publishing giant Macmillan science and education looks set to gain from Springer's scale, Nature (January 15, 2015). Available at http://www.nature. com/news/nature-owner-merges-with-publishing-giant-1.16731.

Vogel, G. (2017). German researchers start 2017 without Elsevier journals. Science, 355(6320), 17-17.

Ware, M., \& Mabe, M. (2015). The STM report: An overview of scientific and scholarly journal publishing. The Hague: International Association of Scientific, Technical and Medical Publishers. Available at: http://www.stm-assoc.org/2015_02_20_STM_ Report_2015.pdf.

Weber-Wulff, D. (2016). Plagiarism detection software: Promises, pitfalls, and practices. In T. Bretag (Ed.), Handbook of Academic Integrity (pp. 625-638). Singapore: Springer.

Wijkhuijs, J. (2015). Dutch Universities Start their Elsevier Boycott Plan. Available at: https://universonline.nl/2015/07/02/dutch-universitiesstart-their-elsevier-boycott-plan.

Wolff, C., Rod, A. B., \& Schonfeld, R. C. (2016). UK survey of academics 2015. Ithaka S+R| Jisc| RLUK. (15 June 2016). Available at: https://repository.jisc.ac.uk/6437/1/ithaka-survey-of-academics2015.pdf. 